\title{
Innovation Front and Technology Linkage
}

\author{
Mari Jibu ${ }^{1} \&$ Yoshiyuki Osabe ${ }^{2}$ \\ ${ }^{1}$ Japan Science and Technology Agency (JST) (5-3 Yonbancho Chiyoda-ku, Tokyo 102-8666), Japan \\ ${ }^{2}$ Japan Patent Office (3-4-3 Kasumigaseki Chiyoda-ku, Tokyo 100-8915), Japan \\ Correspondence: Mari Jibu, Japan Science and Technology Agency (JST) (5-3 Yonbancho Chiyoda-ku, Tokyo \\ 102-8666), Japan
}

Received: February 2, 2016 Accepted: February 16, 2016 Online Published: February 21, 2016

doi:10.11114/bms.v2i1.1393 URL: http://dx.doi.org/10.11114/bms.v2i1.1393

\begin{abstract}
This paper presents new indicators of knowledge flows by linking scientific articles to patents. The citations between scientific articles and patents have been analyzed since Narin started the study of science linkage, which is seen in administrative process as patent examiners refer scientific articles in examining a patent (Narin, 1988, 1997). The new indicators introduced in this paper, "Innovation Front" and "Technology Linkage," are considered important, especially for policy-makers and strategy planners. These new indicators show that innovation in biotechnology field depends on a wide range of scientific knowledge and elicit a new geography of innovation hot spots.
\end{abstract}

Keywords: bibliometric analysis, patent analysis, cluster analysis, co-citation analysis, knowledge flow, innovation

\section{Introduction}

\subsection{Introduce the Problem}

Japan Science and Technology Agency (hereafter JST) is one of the funding agencies in Japan with aim of promoting technology transfers and innovation. In order to provide appropriate funding to the right place, development of new indicators for evaluation of funding effects is key issue. This made JST start the evaluation project.

Japan 4th Science and Technology Basic Plan was approved by the government in 2011, focusing on the evidence-based policymaking. It reads that the government shall promote a "Science for Science, Technology and Innovation policy" in order to plan new policies based on objective grounds (evidence) and use the results of the evaluation and verification for PDCA cycle. This reflected the criticism that policies had not been implemented based on scientific evidence. This is because a systematic database for policy making was non-existent and not available at the time. Each governmental agency or committee conducts a research of evaluation system in terms of policy making and planning. In spite of the urgent need to evaluation study, JST has successfully been able to meet the requirements because we were preparing for this kind of needs in anticipation of the 4th Science and Technology Basic Plan.

JST is a funding agency to support the technology transfer and creation of innovation. As such, it is important to take a look at the contribution of its funding. JST takes the view that Non-patent literature (NPL) in patents is considered to provide an indicator of knowledge flows between science base and innovation system. JST has developed as such an indicator, the "Technology Linkage" for analysis of the impact of research papers on patent applications. JST has also developed the "Innovation Front" for viewing specific research areas where science significantly influences technology by calculating co-citation between patents and research papers (Jibu 2011). Furthermore, JST develops analytical methods to enable visualization of the Technology Linkage and Innovation Front.

\subsection{Innovation Processes}

In order to promote innovation, it is necessary to analyze the process of innovation. The process of innovation is a chain process of the two intellectual activities, "knowledge embodiment (development)" and "knowledge creation (research)" by Yamaguchi (Yamaguchi 2010). He facilitates the visualization of innovation process in so-called "innovation diagram" by dividing the innovation process into 2 axis, that is, in the axis of the "knowledge embodiment" and in the axis of the "knowledge creation" (See Fig.1). When the development of technology becomes deadlocked (A' in Fig.1), it is necessary to review the knowledge in science level ("Induction" in Fig.1) and push forward with science research ("Abduction" in Fig.1) in order to overcome the deadlock and to generate new innovation (A* in Fig.1). It will be 
possible to make a breakthrough and generate innovation by following the actions above. Moreover, by linking science to technology, we can analyze the innovation process from A' to $A^{*}$ via $S$ and $\mathrm{P}$ in Fig.1

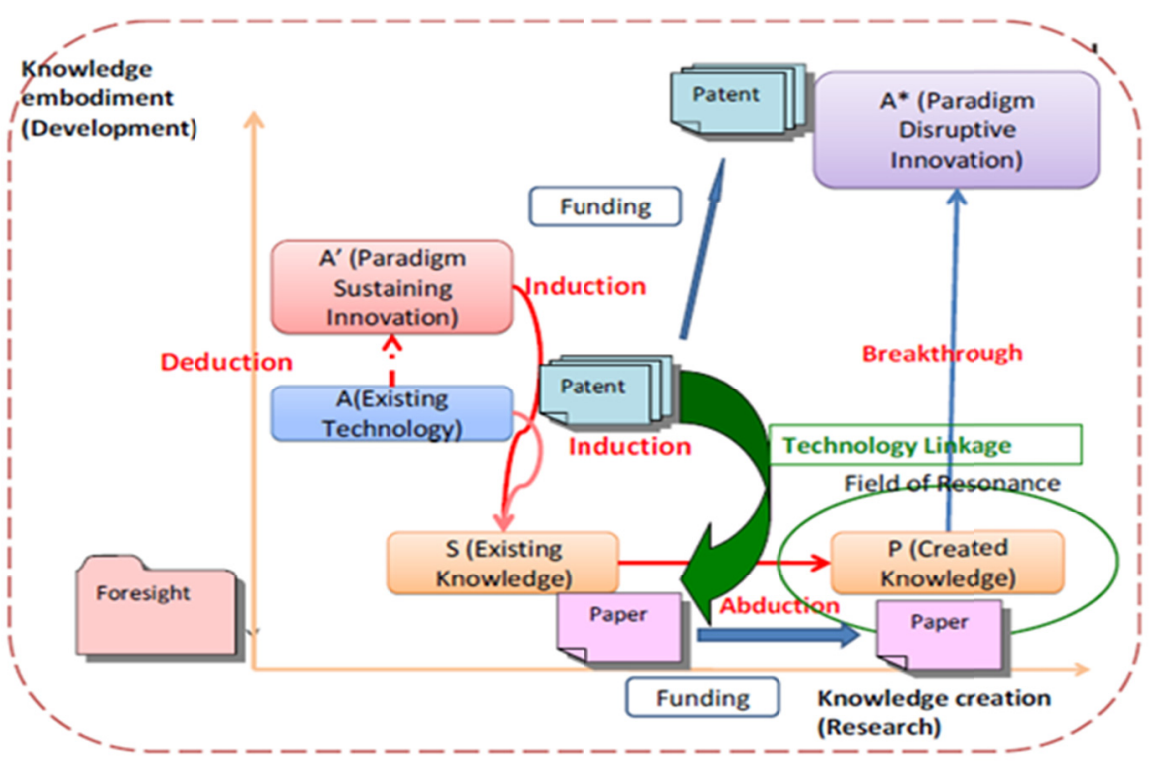

Figure 1. Innovation Process and Scientometrics

Fig. 1 shows an attempt to comprehensively understand and visualize the innovation process by embedding the functions such as bibliometric analysis, patent analysis and cluster analysis into innovation diagram. The linkage between patents and papers is important to gain an evidence-based understanding of the innovation process such as the review of science from existing technology ("Induction" in Fig.1). In the reference cited by patent examiners, we can create an index called the science linkage index, such as the share of non-patent literature (NPL) citations and the number of forward citations per cited patents, which may show whether a patent is science-oriented or technology-oriented. It is saying that backward citations to NPL show how close a patented invention is to scientific knowledge, whereas forward patent citations show the importance of a patent for the development of new technologies.

Our "Technology Linkage" can give the information on which category or area cited papers are classified into, by matching each of cited papers with the bibliography of Thomson Reuters "Web of Science", which is not only analysis use but provides a list of references in patent families. Technology Linkage makes the analysis following possible: for example, scientific knowledge linked with specific technology areas, or scientific knowledge linked with a patent family which is highly influential in the technology world (Jibu 2011).

\section{Methodology}

\subsection{Database}

The databases and technologies used in the Technology Linkage and Innovation Front are as follows:

Papers: Thomson Reuters "Web of Science”, "Essential Science Indicators"

Patents: Thomson Reuters "Derwent World Patents Index", "Derwent World Patents Citation Index"

\subsection{Classification}

\subsubsection{Papers}

(1) 272 subjects from Thomson Reuters "Web of Science" for Technology Linkage

(2) 22 category codes from Thomson Reuters "Essential Science Indicators" for Innovation Front

\subsubsection{Patents}

(1) IPC Codes for ICT, biotechnology, environment-related technologies, nuclear energy and fuel cells (OECD, 2008).

(2) ECLA codes for nanotechnology (OECD, 2008)

\subsection{Technology Linkage}

Patents were extracted from Derwent World Patents Index using the International Patent Classification (IPC) system. Patents in biotechnology are extracted by using the list of IPC codes, which is identified for the biotechnology patents by OECD (OECD, 2008). Cited articles of the patents (backward citation to NPL) were linked with papers of Web of 
Science by Thomson Reuters.

\subsection{Innovation Front}

(1) Extract two arbitrary papers which published between 2006 and 2010 from "Essential Science Indicators," calculate the forward co-citation frequency by patents in "Derwent World Patents Citation Index" and calculate frequencies of forward citations patents in the two arbitrary papers.

(2) Derive cosine coefficient $\mathrm{N}$ from (1.1).

$$
N=F(A, B) / \sqrt{F(A) \times F(B)}
$$

$$
F(A, B)>=2
$$

where A, B represent arbitrary papers, F (A), F (B) represent the cited frequency of the arbitrary papers, F (A, B) represents the co-cited frequency of the arbitrary papers. Define $\mathrm{F}(\mathrm{A}, \mathrm{B})$ is larger than or equal to 2 .

(3) Define $\mathrm{N}>=0.3$. ( $\mathrm{N}$ is larger than or equal to 0.3 )

(4) Compile the papers extracted under condition (3) as nodes, connect the linkage relationship between papers with the edge function, and visualize the network, using Cytoscape Web.

\section{Analytical Results}

\subsection{Technology Linkage}

Technology Linkage can be useful in analyzing the relationship between patents and papers. It contributes understanding the relationship between technological areas of patent family and scientific subjects of cited papers. "Technology-science linkages" of patents have also been discussed at OECD in the section of "Connecting to Knowledge" in OECD Science, Technology and Industry Scoreboard 2011 (OECD, 2011). OECD developed indicators such as the share of non-patent literature (NPL) citations and the number of forward citations per cited patent. It is saying that backward citations to NPL show how close a patented invention is to scientific knowledge. OECD analyzes that, since the proportion of backward citations to NPL is the highest in biotechnology, patented inventions in biotechnology have a close linkage to scientific knowledge comparing to those in other technologies. According to our study, the proportion of backward citations to scientific articles by patents in biotechnology account for $97 \%$. In "Technology Linkage", cited articles are classified into each category or area, by matching each of cited articles with the bibliography of Thomson Reuters "Web of Science", which is not only analysis use but provides a list of references in patent families. Technology Linkage makes the analyses following possible: for example, scientific knowledge linked with specific technology areas, or scientific knowledge linked with patent family which is highly influential in the technology world.

Subjects link with Biotechnology Patents



Source: Thansoon Revters "Web of Science," "Derwent World Patents inder" and "Dermet Patents Civion inder"

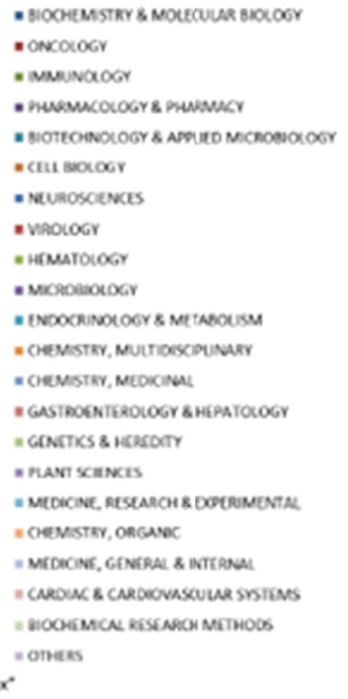

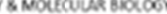

- nuvenucologrs mulawar



- vinotocr

- homatocos

- enoconnotoer s metranouse

- coevestar, multiolscipumer

- onensing, meocina

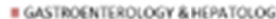

- Gonctics s icarodr

AMCH S DOTUNEVTA:

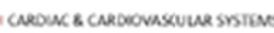

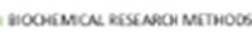

Figure 2. Subjects linked with Biotechnology Patents (2006-2010) 
Fig.2 shows which science subjects link with biotechnology patents from 2006-2010. The ratio of the number of papers in "biochemistry \& molecular biology" is the highest which accounts for $14.3 \%$, followed by "oncology" and "immunology" which account for $11.3 \%$ and $9.2 \%$ respectively. It is found that patent classified in biotechnology have highly strong linkage with these subjects.

Table 1. The number of combinations, subjects of papers and IPC code.

\begin{tabular}{|c|c|c|c|}
\hline Rank & Subject & IPC & Number \\
\hline 1 & Oncology & A61P-35/00 & 1902 \\
\hline 2 & Oncology & C12Q-1/68 & 1716 \\
\hline 3 & $\begin{array}{l}\text { Biochemistry \& } \\
\text { Molecular Biology }\end{array}$ & C12N-15/09 & 1419 \\
\hline 4 & Oncology & G01N-33/574 & 1222 \\
\hline 5 & $\begin{array}{l}\text { Biochemistry \& } \\
\text { Molecular Biology }\end{array}$ & C12Q-1/68 & 1197 \\
\hline 6 & Oncology & C12N-15/09 & 1073 \\
\hline 7 & Oncology & $\mathrm{G} 01 \mathrm{~N}-33 / 53$ & 1024 \\
\hline 8 & $\begin{array}{l}\text { Biochemistry \& } \\
\text { Molecular Biology }\end{array}$ & $\mathrm{C} 07 \mathrm{H}-21 / 00$ & 1018 \\
\hline 9 & Oncology & A61K-39/395 & 1016 \\
\hline 10 & $\begin{array}{l}\text { Biochemistry \& } \\
\text { Molecular Biology }\end{array}$ & A61P-35/00 & 945 \\
\hline 11 & $\begin{array}{l}\text { Biochemistry \& } \\
\text { Molecular Biology }\end{array}$ & C07H-21/04 & 894 \\
\hline 12 & $\begin{array}{l}\text { Biochemistry \& } \\
\text { Molecular Biology }\end{array}$ & $\mathrm{C} 12 \mathrm{~N}-5 / 10$ & 884 \\
\hline 13 & Immunology & A61K-39/00 & 852 \\
\hline 14 & $\begin{array}{l}\text { Biochemistry \& } \\
\text { Molecular Biology }\end{array}$ & G01N-33/53 & 851 \\
\hline 15 & $\begin{array}{l}\text { Biochemistry \& } \\
\text { Molecular Biology }\end{array}$ & C07K-14/435 & 839 \\
\hline 16 & $\begin{array}{l}\text { Biochemistry \& } \\
\text { Molecular Biology }\end{array}$ & A61K-38/00 & 811 \\
\hline 17 & Oncology & C07H-21/00 & 799 \\
\hline 18 & Oncology & A61K-38/00 & 791 \\
\hline 19 & Oncology & A61P-43/00 & 776 \\
\hline 20 & Immunology & C12N-15/09 & 755 \\
\hline
\end{tabular}

Table 1 shows the number of combinations, subjects of papers and IPC Codes. The highest number of combinations is (A61P35/00, Oncology), followed by (C12Q1/68, Oncology) and (C12N15/09, Biochemistry \& Molecular Biology) ${ }^{1}$.

According to the chain-linked model of innovation, basic research in the first and foremost stage contributes not only to existing knowledge but also innovation coming, especially it is of particular note in the biotechnology field. Research in oncology directly and indirectly influences on technologies of Antineoplastic agents and measuring or testing processes involving enzymes or micro-organism.

\subsection{Innovation Front}

"Innovation Front" analyzes articles cited in patent families by co-citation analysis. Since articles cited in patent families are close to technology, it is possible to find major researchers and scientific specialties of articles which influence technology. Thomson Reuters publishes papers with high impact in Science Watch by assigning them as a research front based on the analysis of co-citation frequency of papers. By using the same approach, JST clusters the top $1 \%$ of the most-cited papers which are co-cited by patents and facilitates their visualization as a cluster having an effect on technology and innovation. It has christened the papers having an effect on technology with "Innovation Front". The figure 3 shows the result of the Innovation Front.

\footnotetext{
${ }^{1}$ A61P: SPECIFIC THERAPEUTIC ACTIVITY OF CHEMICAL COMPOUNDS OR MEDICINAL PREPARATIONS A61P35/00: Antineoplastic agents C12Q: MEASURING OR TESTING PROCESSES INVOLVING ENZYMES OR MICRO-ORGANISMS

C12Q1/68: involving nucleic acids C12N: MICRO-ORGANISMS OR ENZYMES; COMPOSITIONS THEREOF

C12N15/09: Recombinant DNA-technology

For other IPCs, see the URL below:

http://www.wipo.int/classifications/ipc/en/
} 


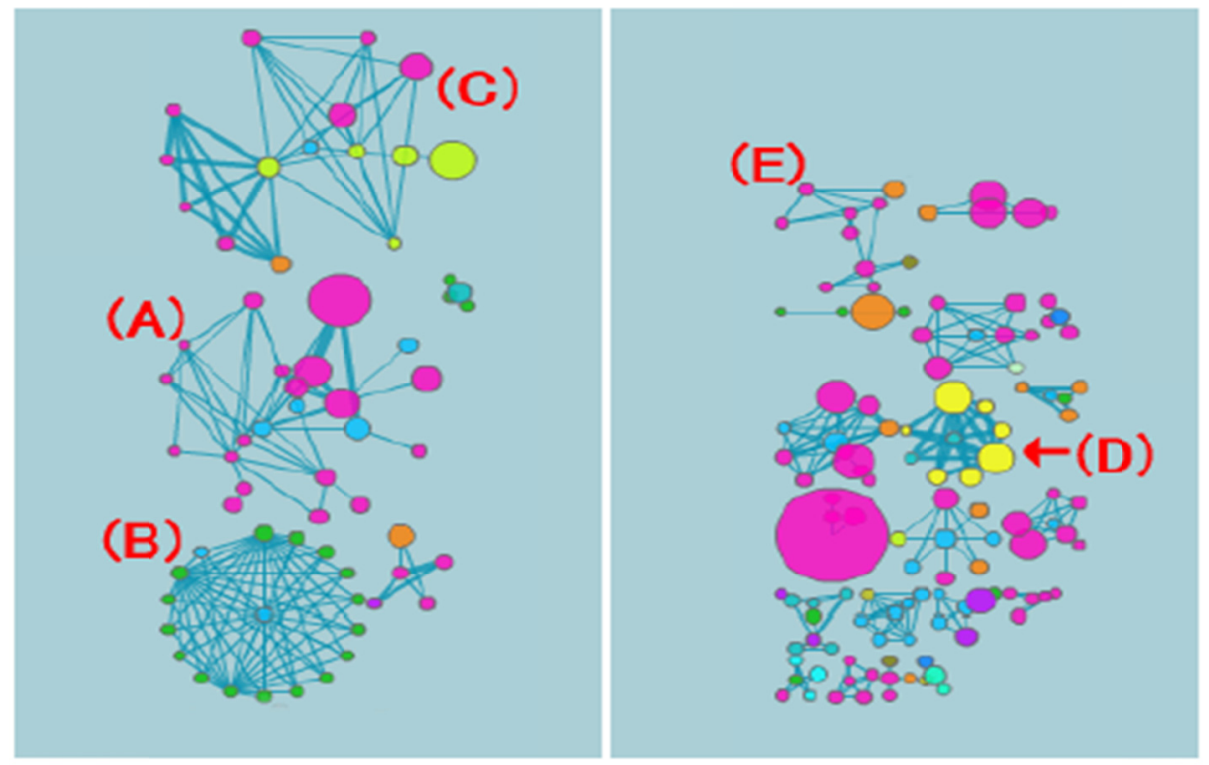

Figure 3. Innovation Front

Nodes express papers and the colours of the nodes represent 22 fields. The size of the nodes represents the number of citations in papers. The line width of edge represents the number of co-citations by patent families. As a result, 24 clusters consisting of 183 papers in total were created. Total citations of patent families are 1,095 and those of papers are 46,038. By looking at the categories, the clinical medicine category is the largest with 83 articles, followed chemistry category with 26 , and the biology/biochemistry category with 24 . The most frequently published journal is Science, with 18 articles followed by NATURE 17, Journal of American Chemical Society 12. Concerning subjects of papers in clusters of Innovation Front: the largest subject is clinical medicine which account for $45.4 \%$, followed by chemistry which accounts for $14.2 \%$.

Cluster (A) is the science field of induced pluripotent stem cells (iPS cells), composed by 22 articles. The core article's title is "Induction of Pluripotent Stem Cells from Adult Human Fibroblasts by Defined Factors", written by Takahashi, K. et. al. and published in Cell, 2007. Cluster (B) is the science field of Aptamor, composed by 18 articles in engineering and chemistry. The core article's title is "Colorimetric Detection of Mercuric Ion (Hg2+) in Aqueous Media using DNA-Functionalized Gold Nanoparticles" written by Lee, J. S. et. al. in NORTHWESTERN University and published in Angewandte Chemie International Edition, 2007. Cluster (C) is the science field of Adipo-cytokine, composed by 15 articles in clinical medicine, Immunology, biology/biochemistry. The core article's title is "TGF beta in the context of an inflammatory cytokine milieu supports de novo differentiation of IL-17-producing T cells" written by Veldhoen, M. et. al. in National Institute for Medical Research and published in Immunity, 2006. Cluster (D) is the science field of Meta-material, composed by 9 articles in physics. The core article's title is "Controlling electromagnetic fields" written by Pendry J. B. et. al. in Imperial College London and published in Science, 2006. Cluster (E) is the science field of MicroRNA and Cardiac Hypertrophy, composed 9 articles in clinical medicine and neuroscience and behavior. The core article's title is "Regulation of cardiac hypertrophy by intracellular signaling pathways", written by Heineke in University of Cincinnati. This Article is published in Nature Reviews Molecular Cell Biology, 2006. 


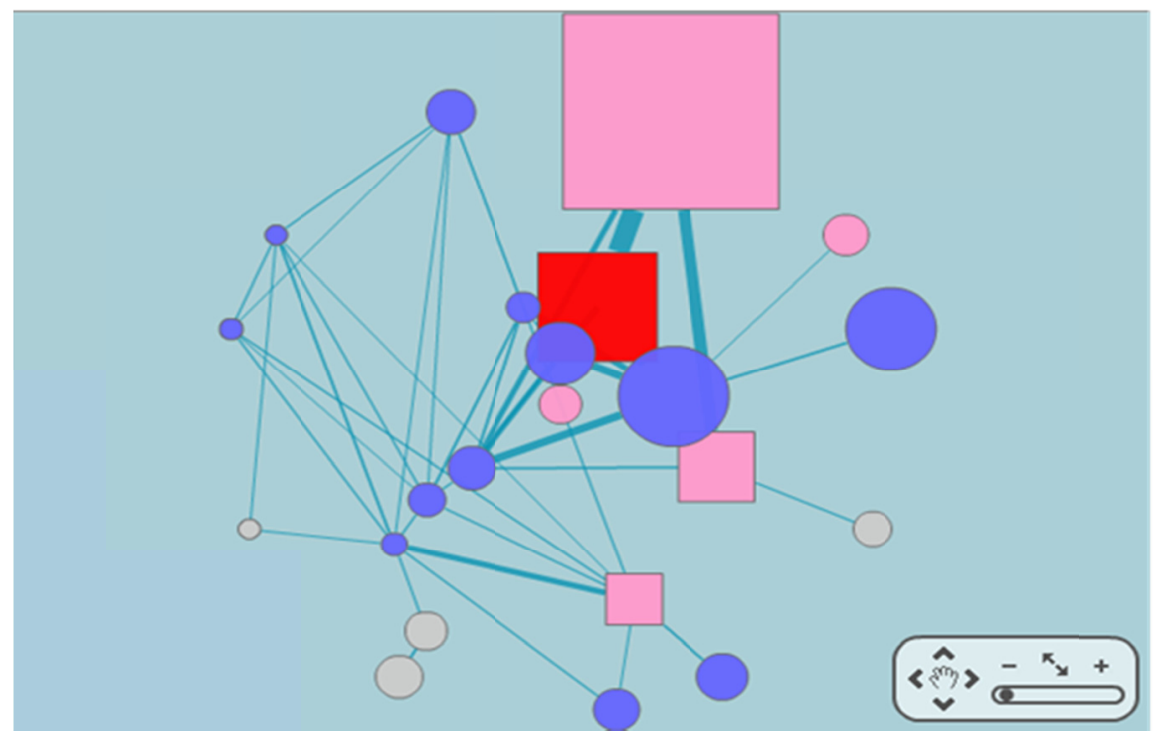

Figure 4. iPS cells cluster in Innovation Front

Fig.4 shows the details of cluster A which is the specific scientific field of iPS cells composed by 22 papers and the number of citations of the papers are 7,517. Squares indicate papers written by Yamanaka group and the Largest square, the core article is "Induction of Pluripotent Stem Cells from Adult Human Fibroblasts by Defined Factors", written by Yamanaka Shinya. This article was published in Cell, 2007. The Nobel Prize in Physiology or Medicine 2012 was awarded jointly to Sir John B. Gurdon and Shinya Yamanaka "for the discovery that mature cells can be reprogrammed to become pluripotent". The Press Release by the Nobel Assembly at Karolinska Institute announced "Induction of pluripotent stem cells from mouse embryonic and adult fibroblast cultures by defined factors" by Takahashi, $\mathrm{K}$ and Yamanaka, S. as one of key publications (The Press Release o by the Nobel Assembly, 2012). This article's target is the iPS cells derived from mouse embryonic and adult fibroblast cultures. On the other hand, the core article of Innovation Front is "Induction of Pluripotent Stem Cells from Adult Human Fibroblasts by Defined Factors" by Takahashi, K and Yamanaka, S. The core article's target of Innovation Front is the iPS cells derived from human fibroblasts. Subjects for study change from in vitro, in vivo, mice, apes and to humans, as the study advances from basic to practical research. Innovation Front is able to find hot scientific papers and specific fields (clusters) composed by the papers that affect the technology close to practical stage. This is the reason why core paper of Innovation Front is the paper that target humans instead of mice or in vitro study. Other papers of iPS cells research also target humans. Papers composed of Innovation Front are almost 6 groups as follows:

Articles of Node 1 were written by International Consortium of Stem Cell Networks which is a consortium of researchers from around the world for making benchmarks for human embryonic stem cell research. Articles of Node 2 were written by Yamanaka S. (Kyoto University) group. Yamanaka group succeeded in converting mice cells and human skin cells into iPS cells. Articles of Node 3 were written by Thomson J. A. (University of Wisconsin) group. Thomson group succeeded in isolating the first human embryonic stem (ES) cells in 1998 and converting human skin cells into iPS cells at almost the same time as Yamanaka group, 2007. Articles of Node 4 were written by Schoeler H. R. (Max Planck Institute) group. Schoeler groups succeeded in reprogramming of adult mouse neural stem cells to pluripotency by requiring Oct4 instead of Oct4, Klf4, c-Myc and Sox2.

Articles of Node 5 were written by Jaenisch R. (MIT) group. Jaenisch group succeeded in reprograming from mature, differentiated mouse B cells to iPS cells and finding alternatives to the potentially cancer-causing retroviruses used to transform the adults cells into iPS cells. Articles of Node 6 were written by Hochedlinger, K. (Harvard University) group. Hoshcedlinger group used an adenovirus to transport the requisite four transcription factors into the DNA of skin and liver cells.

\section{Conclusion}

This paper proposes new indicators: "Technology Linkage" and "Innovation Front" for measuring knowledge flows. Technology Linkage shows the relationship between technology and scientific knowledge, especially what kind of scientific knowledge a technology is based on. Innovation Front shows "new geography of innovation hot spots."

Our main findings from indicators, Innovation Front and Technology Linkage, are as follows; 
(1) Citations to scientific articles by patents in biotechnology account for $97 \%$.

(2) Technologies in biotechnology are based on a wide range of scientific knowledge: the largest subject is Biochemistry \& Molecular Biology which accounts for 14.3\%, followed by Oncology and Immunology which account for $11.3 \%$ and $9.2 \%$ respectively.

(3) The diversity of scientific sources contributes to innovation in biotechnology.

(4) Subjects of papers in clusters of Innovation Front: the largest subject is clinical medicine which accounts for 45.4\%, followed by chemistry which accounts for $14.2 \%$.

(5) Specific science areas recognized as innovation hot spots 2006-2010 are induced pluripotent stem cells, Adipo-cytokine and MicroRNA and Cardiac Hypertrophy.

Taken together, we consider our results help illuminate new indicators for knowledge flow for innovation. Future work will be built on our result with other valuable data, for example, product data and intangible assets.

\section{Addendum}

Note that the opinions expressed in this paper are those of the authors and do not represent those of the institutions that the authors belong to.

\section{References}

Booth, B., \& Zemmel, R. (2004). Prospects for Productivity. Nature Reviews Drug Discovery, 3, 451-456. http://dx.doi.org/10.1038/nrd1384

Jibu, M. (2011). Analysis Achievements of JST Operations through Scientific Patenting: Linkage between Patents and Scientific Papers. Atlanta conference on Science and Innovation Policy, IEEE. 214-220. http://dx.doi.org/10.1109/acsip.2011.6064473

Jibu, M., \& Osabe, Y. (2014). Refined R\&D Indicators for Pharmaceutical Industry. Future Information Technology, Lecutre Notes in Electrical Engineering, 309, 549-554. http://dx.doi.org/10.1007/978-3-642-55038-6_86

Lerner, J. (1994). The Importance of Patent Scope: An Empirical Analysis. The RAND Journal of Economics. 25(2), 219-333. http://dx.doi.org/10.2307/2555833

Narin, F., \& Pozek, R. P. (1988). Bibliometric Analysis of US Pharmaceutical Industry Research Performance, Research Policy, 17, 317-330. http://dx.doi.org/10.1016/0048-7333(88)90039-X

Narin, F., Hamilton, K., \& Olibastro, D., (1997). The increasing linkage between US technology and public science. Research Policy 26, 317-330. http://dx.doi.org/10.1016/S0048-7333(97)00013-9

OECD. (2008). Compendium of Patent Statistics, 2008. Organization for Economic Co-operation and Development.

OECD. (2011). OECD Science, Technology and Industry Scoreboard 2011: Innovation and Growth in Knowledge Economics. Organization for Economic Co-operation and Development.

http://dx.doi.org/10.1787/sti_scoreboard-2011-en

OECD. (2013). OECD Science, Technoogy and Industry Scoreboard 2013: Innovation for Growth. Paris, France OECD Publishing. http://dx.doi.org/10.1787/sti_scoreboard-2013-en

Porter, A. L., \& Ashton, W. B. "Foresight in the USA" in The Handbook of Technology Foresight edited by Luke Georghiou, Jennifer C. Harper, Michael Keenn, Ian Miles and Rafael Popper Edward Elgar Publishing Limited p154 2008.

The Nobel Assembly at Karolinska Institute. (2012), Press Release. The Nobel Assembly at Karolinska Institute. http://www.nobelprize.org/nobel_prizes/medicine/laureates/2012/press.html Accessed 1, February 2016

Yamaguchi, E. (2010). Innovation theory leading to breakthrough -How will the memory device industry face the "post-Moore" future?, Oyo Buturi, 79(12), 1077-1083.

\section{(cc) $\mathrm{EY}$}

This work is licensed under a Creative Commons Attribution 3.0 License. 